\title{
One month to go!
}

\section{Looking forward to BDIA Dental Showcase 2022}

BDIA Dental Showcase is a free, two-day event which will provide over 10,000 attendees the opportunity to gain the latest insights, be inspired, and learn how other dental professionals have been overcoming industry-wide challenges at ExCeL, London, 25-26 March 2022. In addition to featuring our first ever 'Question Time' themed debate on the future of dentistry, the event will feature six CPD theatres, over 80 expert speakers, 250 exhibitors and will have thousands of products on display, making this the perfect place to reconnect with the dental community.

\section{Six CPD-certified theatres to enhance your professional development}

Sara Hurley, the Chief Dental Officer (CDO) for England, and her team will be hosting a series of presentations at the CDO Zone and will be covering subjects on sustainability, regional and local clinical leadership, systemic health and workforce. The CDO's deputies, Rebecca Harris and Jason Wong, will also be at the CDO Zone throughout the show. Speaking ahead of the event, Sara said: 'My keynote address will cover the transition to recovery from COVID19 as well as the next steps to system reform, and I look forward to seeing as many people as possible over the two days. There's a great sense of optimism in finally getting together in person again to exchange ideas, experiences and plans for the future with colleagues across the industry, which is really encouraging.

Returning for another year, the Clinical Theatre, sponsored by Philips, will provide CPD-accredited lectures focusing on new developments in clinical procedures; sessions include Philips, Tif Qureshi, Coltene, Voco, Align Technology, DMG and Cavendish Imaging. Meanwhile, the Oral Health Theatre, sponsored by GSK, will offer a wide range of CPD-accredited presentations from GSK, Waterpik, Dentisan, Dental Monitoring, Listerine and the British Fluoridation Society, aimed at all dental healthcare professionals.

Appealing to practice owners, managers and directors, the Business Theatre will host lectures from Simon Gambold, Dental Elite, Frank Taylor \& Associates, Medi Holdings, Samera and Dodd \& Co, plus panel discussions from the Business Confidence Forum, supported by the Association of Dental Administrators and Managers.

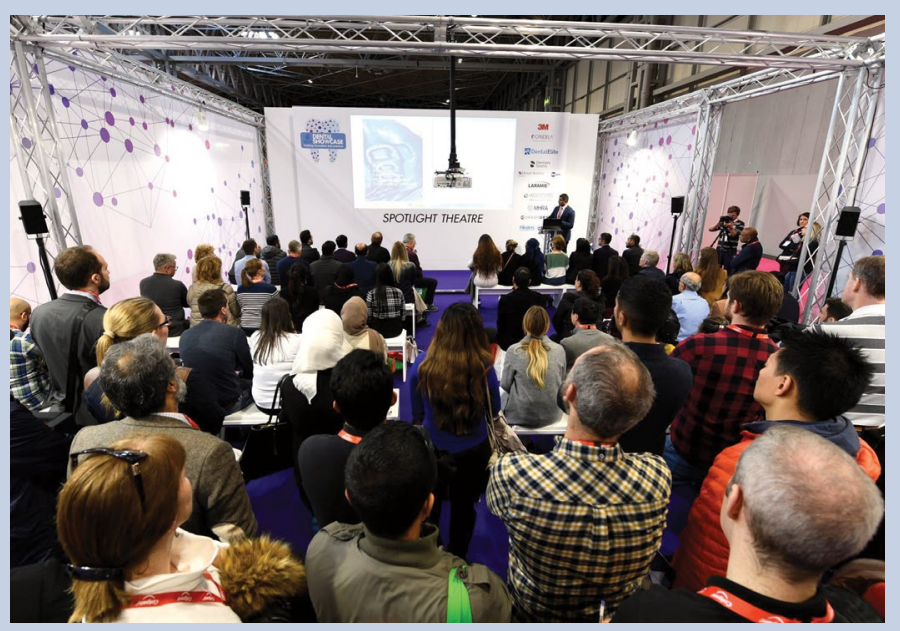

\section{$\frac{10}{M}$ DENTAL BDIA SHO NCASE 25-26 March, 2022 - ExCeL London}

New for 2022, the British Association of Private Dentistry Theatre will be staging their own inaugural lecture theatre, featuring a range of discussions and thought-provoking panel debates about the future of dentistry, changes in management styles plus the latest in finance.

Following the success of Dental Update's webinar series that successfully united the profession during the most difficult period of the pandemic, the Update Webinar Theatre, sponsored by Oral-B and Denplan, will reunite those involved in the initiative, including members of the Dental Update editorial board, leading clinicians and speakers.

\section{Exhibition}

Over 250 exhibitors will be pulling out all the stops to make the 2022 exhibition the best yet. This fantastic platform provides visitors the chance to meet the faces behind the brands, explore the latest innovations, discuss the newest techniques, and source thousands of products that play a fundamental role in your working lives.

Being able to compare a vast range of products and services under one roof will save both time and money during your visit; not to mention, the event is free to attend and is held across Friday and Saturday, providing you flexibility to adjust your working schedule accordingly.

\section{Innovative products and exclusive deals!}

A wide variety of products will be available, including dental implants and prostheses, hand instruments, impression materials, PPE, restoratives, bonding agents finishing and polishing products, suction and evacuation products and so much more.

Don't miss out on the exclusive discounts, special offers and live product demonstrations only available to attendees!

- Discover the latest dental chairs from companies such as Belmont, A-Dec, Planmeca, Prestige Medical and more

- Check out digital equipment including intraoral scanners and 3D printers from Henry Schein Dental and Cavendish Imaging

- Compare hand instruments from suppliers Coltene, Swallow and many more

- Discuss surgery refits with companies such as Anglian Dental

- Consider all your options with Braemar Finance, Performance Finance Ltd, Samera and FTA Finance.

To keep up to date with the latest procedures and techniques in dentistry, including new speakers, sessions and exhibitors, register for free to attend the BDIA Dental Showcase at ExCeL, London, 25-26 March 2022.

For more information and to register, visit www.dentalshowcase.com. 